\title{
PADRÕES CLIMATOLÓGICOS DE PRECIPITAÇÃO E TEMPERATURA DO AR ASSOCIADOS AO RENDIMENTO DO FEIJÃO COMUM EM MINAS GERAIS
}

\author{
SANTOS, Luiz Fernando dos - santoslf.met@gmail.com \\ Universidade Federal de Itajubá / UNIFEI \\ MARTINS, Fabrina Bolzan - fabrinabm@gmail.com \\ Universidade Federal de Itajubá / UNIFEI
}

GARCIA, Sâmia Regina - samiarg@gmail.com

Universidade Federal de São Paulo / UNIFESP

\begin{abstract}
RESUMO: O feijão comum (Phaseolus vulgaris L.) apresenta grande importância nutricional na alimentação do brasileiro, além de relevante contribuição no cenário socioeconômico nacional e internacional. No estado de Minas Gerais, o segundo maior produtor nacional, o feijão pode ser cultivado em três épocas diferentes. Essas épocas podem apresentar condições climáticas distintas, sendo que, dentre essas condições, o feijão exige uma faixa de temperatura ótima e precipitação bem distribuída ao longo de seu ciclo para alcançar o seu máximo rendimento. Com isso, o objetivo desse estudo foi analisar o comportamento macroclimático das anomalias de temperatura máxima e mínima do ar (Tmáx e Tmín, respectivamente), juntamente com a distribuição, intensidade e persistência da precipitação e, assim, entender suas influências sobre o rendimento médio do feijão (RMF) em cada safra e macrorregião (MMG). A variabilidade de Tmáx e Tmín e, principalmente, as características pluviométricas em todas as MMG foram capazes de influenciar nos maiores e menores valores de RMF durante o período de estudo.
\end{abstract}

PALAVRAS-CHAVE: agrometeorologia, safra, agricultura, semeadura

\section{CLIMATOLOGICAL PATTERNS OF PRECIPITATION AND AIR TEMPERATURE ASSOCIATED WITH THE COMMON BEAN YIELD IN MINAS GERAIS}

\begin{abstract}
The common bean (Phaseolus vulgaris L.) has great nutritional importance to the Brazilian diet and a relevant contribution to the socioeconomic scenario. In Minas Gerais state, the second largest national producer, beans can be grown in three different seasons. Those seasons can get different climatic conditions like an optimum temperature range and precipitation well distributed throughout its cycle toward reach a maximum yield. Thus, the aim of this study was to analyze the macroclimatic behavior of the maximum and minimum air temperature anomalies (Tmáx and Tmín, respectively), and the distribution, intensity and persistence of the precipitation, understanding their influence on the average yield of the beans (RMF) in each crop and macroregion (MMG). The variability of Tmáx and Tmín and, mainly, the rainfall characteristics on all of the MMG were able to influence the higher and lower values of RMF.
\end{abstract}

KEYWORDS: agrometeorology, crop, agriculture, seeding

PATRONES CLIMATOLÓGICOS DE PRECIPITACIÓN Y TEMPERATURA DEL AIRE ASOCIADOS AL RENDIMIENTO DEL FRIJOL EN MINAS GERAIS

RESUMEN: El frijol (Phaseolus vulgaris L.) presenta gran importancia nutricional en la alimentación del brasileño, además de relevante contribución en el escenario socioeconómico nacional e internacional. En el estado de Minas Gerais, el segundo mayor productor nacional, el frijol se siembra en tres épocas distintas, las quales pueden presentar condiciones climáticas distintas. El cultivo de frijol se ve favorecido en un rango de temperatura óptima y precipitación bien distribuida a lo largo de su ciclo para alcanzar su máximo rendimiento. Preso, el objetivo de este estudio fue analizar el comportamiento macroclimático de las anomalías de temperatura máxima y mínima del aire (Tmáx y 
Tmín, respectivamente), junto con la distribución, intensidad y persistencia de la precipitación y, así, entender sus influencias sobre el rendimiento medio del frijol (RMF) en cada cosecha y macrorregión (MMG). La variabilidad de Tmáx y Tmín y, principalmente, las características de precipitación en todas las MMG fueron capaces de influir en los mayores y menores valores de RMF durante el período de estudio.

PALABRAS CLAVE: agrometeorología, cosecha, agricultura, siembra

\section{INTRODUÇÃO}

O feijão comum (Phaseolus vulgaris L.) compõe a refeição básica do brasileiro, é uma fonte acessível de proteína e pode ser cultivado em todo o território nacional (SILVA et al., 2011). Tem como principais produtores o Paraná, Minas Gerais (MG), Goiás, São Paulo e Bahia. Segundo o Instituto Brasileiro de Geografia e Estatística (IBGE, 2016), o estado de MG aparece como o segundo maior produtor nacional com $20 \%$ da produção.

O caráter sazonal dessa cultura possibilita três épocas distintas de semeadura em MG: $1^{\text {a }}$ safra ou "das águas" (com semeadura variando de agosto a novembro), $2^{a}$ safra ou "da seca" (janeiro a março) e $3^{a}$ safra, de inverno ou irrigada (abril a julho). Tais datas são definidas para atender as necessidades hídricas e térmicas de cada subperíodo a fim de atingir o pleno desenvolvimento e máxima produtividade (BARBOSA; GONZAGA, 2012; EMBRAPA, 2014; VIVAN et al., 2015).

Apesar dos avanços tecnológicos ao longo das últimas décadas, a produção agrícola ainda continua sendo dependente do tempo e do clima. Os serviços agrometeorológicos tornaram-se essenciais devido à variabilidade climática, aos eventos extremos associados e às alterações climáticas que impactam diretamente a produção agrícola (WMO, 2010; ASSUNÇÃO; WANDER, 2014; JONES et al., 2016). Cerca de $80 \%$ da variabilidade da produção agrícola ocorre devido às condições meteorológicas durante seu ciclo, uma vez que os agricultores não podem controlar tais fenômenos naturais (HOOGENBOOM, 2000; HEINEMANN et al., 2009; ASSUNÇÃO; WANDER, 2014), e estes desafios têm repercussões em termos de condições socioeconômicas em geral, especialmente nos países em desenvolvimento. Nesse contexto, cabe destacar que a produção do feijão é variável entre os anos e comumente observam-se perturbações e inconstâncias no cenário comercial (DOURADO NETO; FANCELLI, 2000) pelo fato da cultura ser pouco tolerante às condições meteorológicas extremas, sobretudo durante o florescimento com relação à temperatura do ar e deficiência hídrica (SILVA et al., 2007; SILVA et al., 2011; EMBRAPA, 2014).

De modo geral, a temperatura do ar, dentro de intervalos ótimos de temperatura, aumenta a velocidade das reações metabólicas, induzindo maior produção fotossintética e outros processos inerentes à produtividade (HEINEMANN et al., 2009; TAIZ; ZEIGER, 2013). No entanto, temperaturas elevadas causam abortamento de flores e vagens, redução do número de grãos por vagem, crescimento vegetativo exagerado e grãos reduzidos, os quais afetam diretamente a duração do ciclo e o rendimento do feijão (CARAMORI et al., 2001; SILVA et al., 2007; HOFFMANN JUNIOR et al., 2007).

Quanto à deficiência hídrica, tem-se que a mesma causa limitações fisiológicas e anatômicas, sendo que o feijoeiro possui baixa capacidade de recuperar-se, principalmente devido ao limitado crescimento radicular (SILVA et

Ano 14 - Edição Especial Dossiê Climatologia de Minas Gerais - NOV 2018 
al., 2011). A presença ou a ausência de precipitação afeta a disponibilidade hídrica do solo, o que influencia a absorção de água e nutrientes pelas raízes (HEINEMANN et al., 2009). Em períodos de estiagem, as principais respostas são a redução da área foliar, modificações no sistema radicular, redução da condutância e fechamento estomático, fatores determinantes na redução da assimilação do carbono e, consequentemente, levam à diminuição da fotossíntese e produtividade, além do atraso na maturação do feijão (DARKWA et al., 2016; MATHOBO et al., 2017). Entretanto, chuvas excessivas reduzem a oxigenação do solo e a atividade radicular, afetando a absorção de água e nutrientes (HEINEMANN et al., 2009).

Existem inúmeros estudos que analisam as influências da temperatura e precipitação sobre o feijão em diversos locais do Brasil (SILVA et al., 2007; MARCO et al., 2012; HEINEMANN et al., 2016, 2017, entre outros). No entanto, a maioria preocupa-se em comparar modelos de simulação do rendimento local (HOOGENBOOM, 2000), não utilizam séries longas de dados observados e nem consideram dados de macroescala. Além disso, não associam a influência da climatologia, em escala superior à local, e respectiva variabilidade dos elementos climáticos no rendimento do feijão, as quais apresentam comportamento distinto nas diferentes regiões brasileiras.

Nesse contexto, no que se refere às características climatológicas da precipitação, cabe ressaltar que MG encontra-se inserido no Sistema de Monção da América do Sul (SMAS). O SMAS desenvolve-se sobre regiões continentais de baixas latitudes em resposta ao contraste térmico entre o continente e regiões oceânicas adjacentes, sendo o maior componente dos regimes de precipitação de verão, caracterizando tal região com inverno seco e verão chuvoso (ZHOU; LAU, 1998; GAN et al., 2004; SANTOS; GARCIA, 2016; GARCIA et al., 2016; 2017; GAN et al., 2016). Os maiores (menores) índices pluviométricos localizam-se na região sudoeste (norte) de MG (ÁVILA et al., 2014; REBOITA et al., 2015). Quanto à temperatura do ar, tem-se grande amplitude térmica, com os maiores (menores) valores médios anuais, acima de $24^{\circ} \mathrm{C}$ (médias entre 14 ${ }^{\circ} \mathrm{C}$ e $18{ }^{\circ} \mathrm{C}$ ) no norte do estado e na divisa com o Espírito Santo (setores montanhosos de MG); valores médios entre $19{ }^{\circ} \mathrm{C}$ e $21^{\circ} \mathrm{C}$ são encontrados na região central do estado (REBOITA et al., 2015; GARCIA et al., 2018). Logo, devido à variabilidade desses elementos climáticos em MG, aliado a carência de estudos básicos dessa natureza, este estudo tem como objetivo analisar as possíveis influências da precipitação e das anomalias das temperaturas mínimas e máximas do ar sobre os dados de macroescala do rendimento médio do feijão, por safra, em quatro macrorregiões do estado.

\section{MATERIAL E MÉTODOS}

Neste estudo foram utilizados os dados referentes ao período de 2003 a 2015 de precipitação diária $\left(\mathrm{mm} \cdot \mathrm{dia}^{-1}\right)$, anomalias de temperatura mínima e máxima do ar (Tmín e Tmáx, ${ }^{\circ} \mathrm{C}$ ) e rendimento médio do feijão ( $R M F, \mathrm{~kg} \mathrm{ha}^{-1}$ ). Optou-se por analisar os dados diários de precipitação em função da importância da magnitude, distribuição e persistência desta variável e as anomalias de Tmín e Tmáx, em função da pouca variabilidade da temperatura média, sendo que, a partir de suas anomalias é possível notar mais explicitamente as variações dos extremos de temperatura. 
Os dados de precipitação foram provenientes do Instituto Nacional de Meteorologia - INMET (Surface Synoptic Observations - SYNOP e Estação Meteorológica Automática), Instituto Nacional de Pesquisas Espaciais (INPE; Plataforma de Coleta de Dados), Centros Estaduais de Meteorologia (CEM), interpolados pelo Centro de Previsão de Tempo e Estudos Climáticos (CPTEC) em uma grade regular com resolução de $0,25^{\circ} \times 0,25^{\circ}$ de latitude e longitude.

Os dados de Tmín e Tmáx foram obtidos de 52 estações convencionais do INMET e o RMF foi obtido do Sistema IBGE de Recuperação Automática (SIDRA), disponível no website <http://www.sidra.ibge.gov.br/>. O período do estudo (2003-2015) é devido à disponibilidade dos dados de RMF.

Por concisão e para facilitar a comparação entre as variáveis e o RMF, dividiu-se o estado em quatro macrorregiões (MMG)(Figura 1): a) MMG - 1: Noroeste, Norte, Jequitinhonha, Vale do Mucuri $\left(18,25^{\circ} \mathrm{S}-14,25^{\circ} \mathrm{S}\right.$ e $47,5^{\circ} \mathrm{W}$ $\left.40^{\circ} \mathrm{W}\right)$; b) MMG - 2: Metropolitana e Vale do Rio Doce $\left(20,25^{\circ} \mathrm{S}-18,25^{\circ} \mathrm{S}\right.$ e $\left.45^{\circ} \mathrm{W}-41^{\circ} \mathrm{W}\right)$; c) MMG - 3: Oeste, Sul, Zona da Mata, Campo das Vertentes $\left(22,75^{\circ} \mathrm{S}-20,25^{\circ} \mathrm{S}\right.$ e $\left.47,25^{\circ} \mathrm{W}-42^{\circ} \mathrm{W}\right)$; d) MMG - 4: Triângulo Mineiro e Central $\left(20,25^{\circ} \mathrm{S}-18,25^{\circ} \mathrm{S}\right.$ e $\left.51^{\circ} \mathrm{W}-45^{\circ} \mathrm{W}\right)$. Cabe ressaltar que essa divisão é consistente com as características climatológicas de temperatura do ar e precipitação no estado (ÁVILA et al., 2014; REBOITA et al., 2015; GARCIA et al., 2018).

O RMF foi obtido para cada MMG (Figura 1), sendo determinado pela média aritmética do RMF de cada mesorregião integrante. Contudo, as séries de RMF apresentaram tendência linear nas MMG (figuras não mostradas), o que dificultaria a comparação entre a precipitação e as anomalias de Tmín e Tmáx, já que as mesmas podem não estar relacionadas necessariamente às condições climáticas, mas influenciadas por outros fatores, como incentivo agrícola (CHAGAS et al., 2004; FARIA et al., 2013; FAO, 2015).

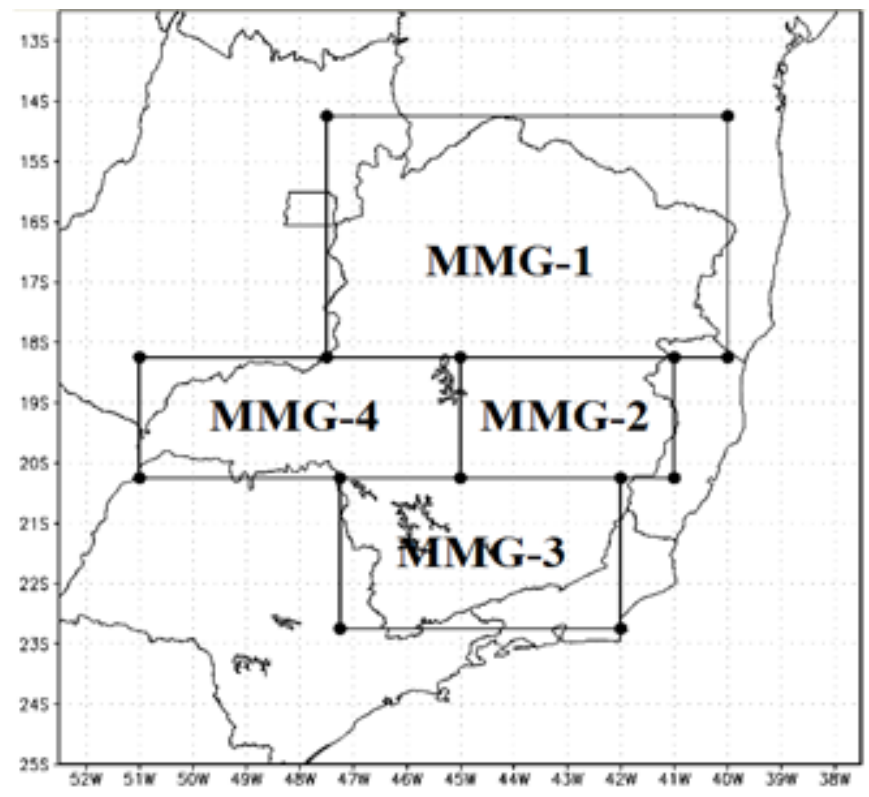

Figura 1 - Divisão das quatro macrorregiões de estudo em Minas Gerais. 
Como o foco da comparação é entender as variações das séries de precipitação, Tmín, Tmáx e do RMF, a tendência linear do RMF foi removida utilizando-se o Método dos Mínimos Quadrados (MMQ), no qual se tem $n$ valores $q 0, \ldots, q n$, cuja ordem numérica de 1 a $n$ está representada por $p 0, \ldots, p n$. Assim, o i-ésimo valor sem tendência linear foi obtido por:

$\left(q_{i}\right)_{s}=q_{i}-\left(A x_{i}+B\right)$

em que $\left(q_{i}\right)_{s}$ é o i-ésimo valor de RMF por safra sem tendência linear; $q_{i}$ é o $i$ ésimo valor de RMF por safra com tendência linear; $n$ é o número total de dados e

$$
\begin{aligned}
& A=\frac{n \sum p q-\sum q \sum p}{n \sum p^{2}-\left(\sum p\right)^{2}} \\
& B=\frac{\sum q-A \sum p}{n}
\end{aligned}
$$

Ainda, para melhor visualização e análise da série de RMF, tais valores foram normalizados a fim de ficarem entre -1 e 1 , por:

$\mathrm{RMF}_{\text {norm. }}=2 *\left[\frac{\mathrm{RMF}_{\mathrm{x}_{s} y^{-}} \text {minn }\left(\mathrm{RMF}_{\mathrm{x}}\right)}{\text { máx }\left(\mathrm{RMF}_{\mathrm{x}}\right)-\min \left(\mathrm{RMF}_{\mathrm{x}}\right)}\right]-1$

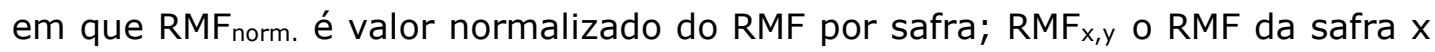
para o ano $y$; mín $\left(R M F_{x}\right)$ e máx $\left(R M F_{x}\right)$ são os valores mínimos e máximos, respectivamente, de RMF da safra $x$ do período estudado (2003-2015).

As anomalias de Tmín e Tmáx foram obtidas por:

$\mathrm{T}_{x, y}^{a}=\mathrm{T}_{x, y}-\overline{\mathrm{T}_{x}}$

em que $T^{\prime}{ }_{x, y}$ é a anomalia de Tmín e Tmáx do ciclo do feijão na safra $x$ e ano $y$; $T_{x, y}$ é a Tmín e Tmáx referente ao ciclo na safra $x$ e ano $y ; \overline{T_{x}}$ é a média de Tmín e Tmáx para as safras $x$ no período total de estudo (2003-2015).

Posteriormente, foi verificada a significância das anomalias. Como os dados de temperatura do ar possuem distribuição normal, a hipótese nula foi assumida para o teste da significância das anomalias, devendo ser atendida a condição:

$-\mathrm{t}_{\mathrm{s}} * \frac{\sigma}{\sqrt{\mathrm{n}-1}}<\mathrm{a}<+\mathrm{t}_{\mathrm{s}} * \frac{\sigma}{\sqrt{\mathrm{n}-1}}$

em que ts é o valor tabelado $(p=0,05)$ da distribuição $t$ de Student correspondente a $n-1, \sigma$ é o desvio padrão, a é a média da amostra e $n$ é o número de dados. Os valores absolutos excedendo $t_{5} * \frac{\sigma}{\sqrt{n-1}}$ são significativos (PANOFSKY e BRIER, 1968; LONGOBARDI; VILLANI, 2010).

Como MG possuiu três safras de cultivo do feijão, as quais variam principalmente em função das datas de semeadura, optou-se por utilizar em cada MMG, a data média de semeadura (DMS) (Tabela 1). A DMS foi baseada a 
partir dos dados de zoneamento agrícola de risco climático disponibilizado pelo Sistema de Consulta à Legislação do Ministério da Agricultura, Pecuária e Abastecimento (SISLEGIS/MAPA), subscritos pela Portaria 209/2013 e 63/2014 de acordo com os tipos de solo (MAPA, 2013, 2014).

Tabela 1 - Data média de semeadura (DMS), em decêndios (período de 10 dias), para $1^{\text {a }}$ safra (safra "das águas"), $2^{a}$ safra (safra "da seca") e $3^{a}$ safra (safra irrigada) de feijão em MG para cada macrorregião, segundo os grupos de cultivares e tipos de solo estudados.

\begin{tabular}{ccccc}
\hline & MMG-1 & MMG-2 & MMG-3 & MMG-4 \\
1 $^{\text {a SAFRA }}$ & 29 a $33(01 \mathrm{nov})^{*}$ & 27 a $34(01 \mathrm{nov})^{*}$ & 25 a $36(25 \text { out })^{*}$ & 28 a $35(01 \mathrm{nov})^{*}$ \\
2 $^{\text {a SAFRA }}$ & 1 a $4(15 \text { jan })^{*}$ & 2 a $5(01 \mathrm{fev})^{*}$ & 1 a $5(25 \text { jan })^{*}$ & 1 a $6(01 \mathrm{fev})^{*}$ \\
3 $^{\text {a SAFRA }}$ & 11 a $15(05 \text { mai })^{*}$ & 20 a $22(25 \text { jul })^{*}$ & 20 a $21(05 \text { jul })^{*}$ & 21 a $23(01 \text { ago })^{*}$ \\
\hline
\end{tabular}

Fonte: Adaptado de MAPA (2013, 2014). *Data média de semeadura (DMS) - início da duração do ciclo do feijão e que corresponde, aproximadamente, à data média de semeadura em cada safra e macrorregião.

Desse modo foi possível determinar o momento da ocorrência média da colheita em cada MMG, através da duração do ciclo do feijão desde a DMS + 90 dias (Figura 2). O limiar de 90 dias foi adotado em função de ser a data média de duração do ciclo do feijão entre os três grupos de hábito de crescimento (tipo I/precoce: ciclo médio de 85 dias; tipo II/médio: ciclo médio de 90 dias; tipo III/tardio: ciclo médio de 105 dias) (DOURADO NETO; FANCELLI, 2000; SILVA et al., 2007), além deste limiar garantir a melhor qualidade das sementes e maior produtividade do feijão (BOTELHO et al., 2010).

Contudo, vale ressaltar que além do feijão poder ser cultivado em três safras, essas safras podem exceder o ano civil. Caso a produção agrícola de alguma safra ultrapasse o ano civil, o IBGE estima a produção total do RMF no ano que for registrada a maior parte da colheita (IBGE, 2016). Esse critério facilita a contabilização do RMF de cada safra e ano.

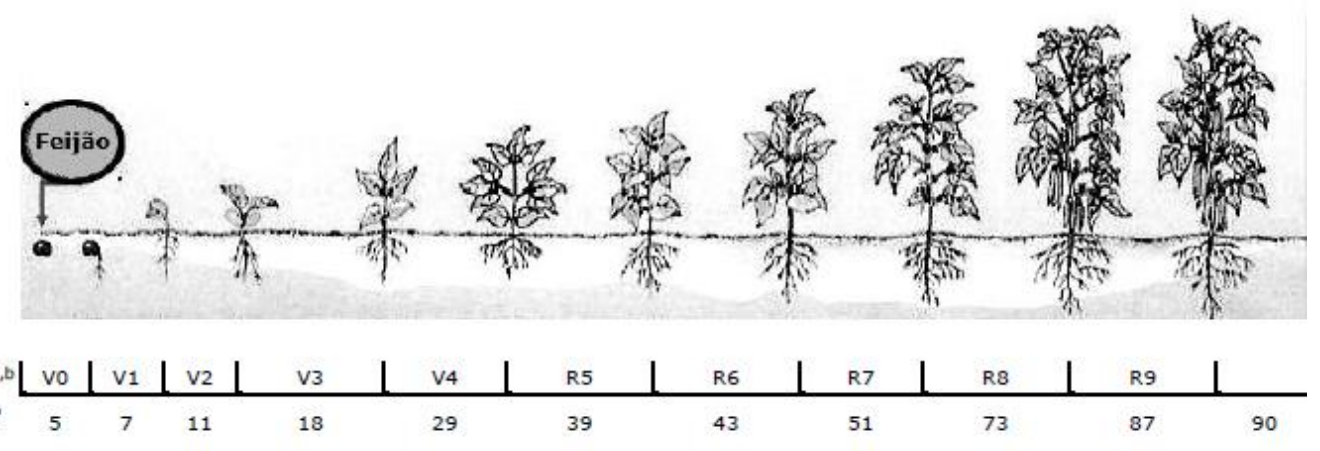

Figura 2 - Escala fenológica do feijão comum e duração média do ciclo de cada subperíodo, considerando a média entre os hábitos de crescimento (I, II, III).

${ }^{a} \mathrm{~V}=$ Vegetativo e $\mathrm{R}=$ Reprodutivo; ${ }^{\mathrm{b}}$ Cada etapa começa quando $50 \%$ das plantas apresentam as condições necessárias do presente estágio; ${ }^{\mathrm{C} D A S}=$ Dias após a semeadura (média). Figura fora de escala. Fonte: Adaptado de CIAT (1983) e Universidade Federal de Viçosa (UFV). 
Assim, a partir da DMS das três safras e em cada MMG, tem-se a possibilidade de analisar o comportamento do feijão no estado e entender como a distribuição, intensidade e persistência da precipitação assim como a existência de anomalias significativas de Tmín e Tmáx durante o ciclo do feijão podem influenciar o RMF.

\section{RESULTADOS E DISCUSSÃO}

A obtenção do RMF por MMG no período de estudo (2003-2015) permitiu gerar um perfil normalizado e sem tendência linear do RMF, por safra, para todo o estado (Figura 3). Verifica-se que em todas as MMG existe uma variação interanual e entre safras do RMF e, na maioria das vezes, as oscilações mais expressivas não coincidem, tanto entre as safras quanto para cada MMG. Isto sugere uma influência das variáveis meteorológicas, principalmente a temperatura do ar (SILVA et al., 2007; PIMENTEL et al., 2013) e precipitação (SILVA et al., 2011; DARKWAN et al., 2017) no RMF em cada uma das MMG. Por exemplo, no ano de 2006, o RMF para a $1^{\text {a }}$ safra na MMG-1 e 2 (Figuras $3 a$ e $3 b$, respectivamente) foram os menores do período em ambas as regiões; na MMG-3 (Figura 3c), apesar de uma tendência de diminuição, a queda não foi tão expressiva como na MMG $^{-1}$ e 2, enquanto que na MMG-4 (Figura 3d) o RMF teve um aumento se comparado aos anos anteriores. Destaca-se a $1^{\text {a }}$ safra de 2013, o qual apresentou considerável diminuição do RMF em todas as MMG (exceto na MMG-3) seguido de aumento do RMF em 2014 (Figura 3).

Por concisão foram selecionados os casos de maiores e menores RMF relativos em cada safra e MMG, associando-os com a precipitação e as anomalias de Tmáx e Tmín. Assim, na MMG-1 os maiores (menores) RMF relativos ocorreram nos anos 2005 e 2009 (2006 e 2013) para a $1^{\text {a }}$ safra, nos anos de 2015 (2013) na $2^{a}$ safra e nos anos de 2013 (2015) na $3^{a}$ safra; na MMG-2 nos anos 2003 e 2014 (2006) na $1^{\text {a }}$ safra, nos anos 2004 e 2012 (2003 e 2010) na $2^{a}$ safra e nos anos 2010 (2011) na 3a safra; na MMG-3 em 2005 (2007) na $1^{a}$ safra, em 2012 (2007 e 2014) na 2a safra e em 2013 (2014) na $3^{a}$ safra; e na MMG-4 em 2011 (2013) na $1^{a}$ safra, em 2003 e 2013 (2011) na $2^{a}$ safra e em 2003 (2006 e 2007) na $3^{a}$ safra. 

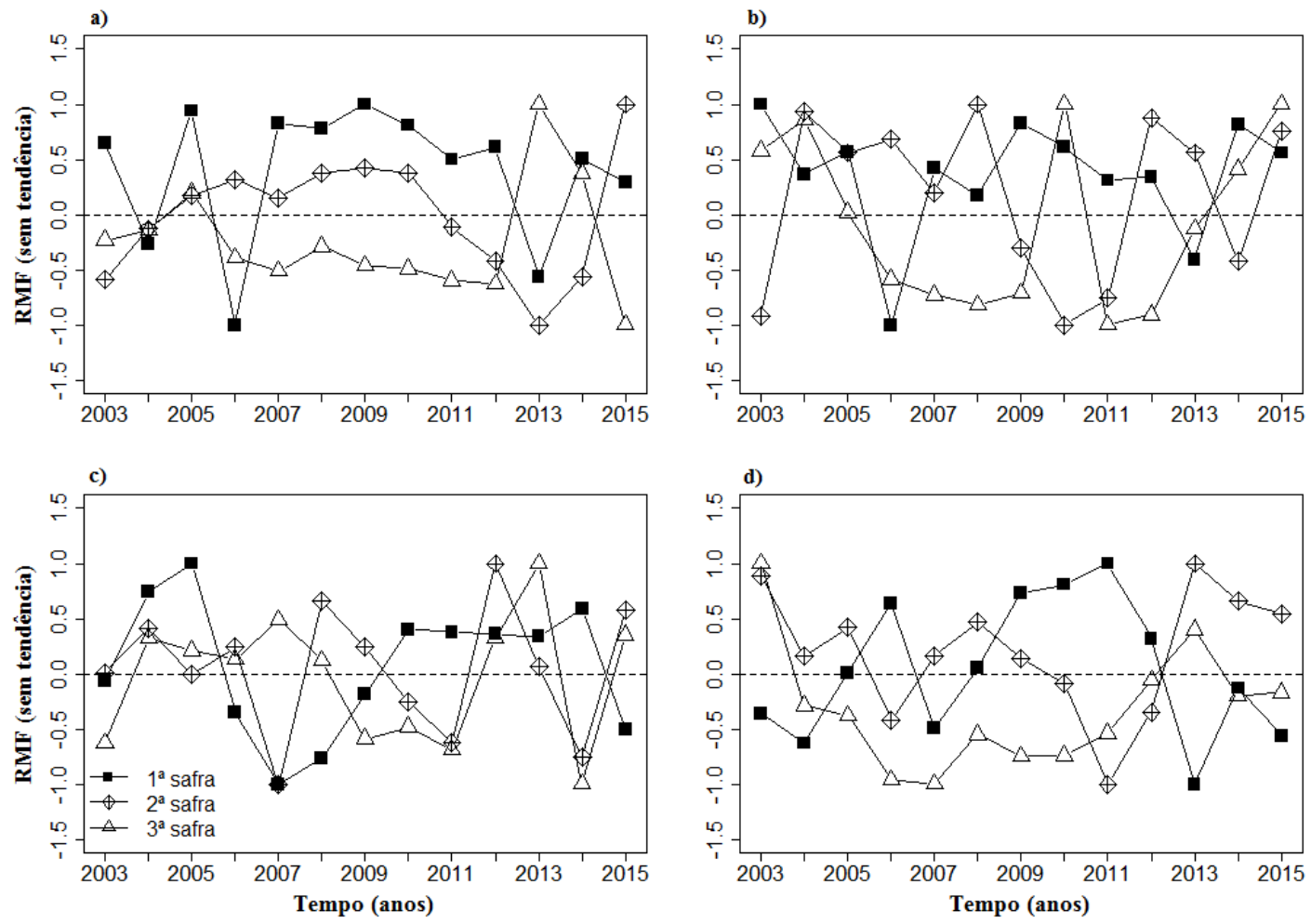

Figura 3 - Série de RMF $\left(\mathrm{kg} \cdot \mathrm{ha}^{-1}\right)$ por safra sem tendência e normalizada para cada macrorregião de MG: a) MMG-1; b) MMG-2; c) MMG-3; d) MMG-4 entre 2003-2015.

Pelo teste $t$ foi possível encontrar os valores significativos das anomalias de Tmín e Tmáx para cada MMG e safra (Tabela 2) e desses limiares selecionar as anomalias significativas de Tmáx e Tmín dentro das safras no período de estudo (Tabela 3 e 4). 
Tabela 2 - Valores limítrofes de significância das anomalias de temperatura máxima (Tmáx) e mínima (Tmín) do ar, pelo teste t de Student, durante o ciclo do feijão nas três safras e quatro nas macrorregiões de MG.

\begin{tabular}{cccc}
\hline MACRORREGIÃO & SAFRA & TMÁX' & TMIN' \\
& S-1 & $\pm 0,66$ & $\pm 0,30$ \\
MMG-1 & S-2 & $\pm 0,61$ & $\pm 0,24$ \\
& S-3 & $\pm 0,49$ & $\pm 0,73$ \\
& S-1 & $\pm 0,74$ & $\pm 0,41$ \\
MMG-2 & S-2 & $\pm 0,51$ & $\pm 0,23$ \\
& S-3 & $\pm 0,47$ & $\pm 0,61$ \\
& S-1 & $\pm 0,60$ & $\pm 0,42$ \\
MMG-3 & S-2 & $\pm 0,55$ & $\pm 0,25$ \\
& $\mathbf{S}-3$ & $\pm 0,54$ & $\pm 0,70$ \\
& $\mathbf{S - 1}$ & $\pm 0,47$ & $\pm 0,35$ \\
MMG-4 & $\mathbf{S - 2}$ & $\pm 0,52$ & $\pm 0,29$ \\
& $\mathbf{S - 3}$ & $\pm 0,65$ & $\pm 0,48$ \\
\hline
\end{tabular}

De maneira geral, independentemente da MMG, a presença de anomalias de Tmáx ou Tmín e chuvas acima ou abaixo da média climatológica impactou no RMF. Analisando primeiramente a $\mathrm{MMG}^{-1}$, nesta macrorregião estão contidos os principais municípios produtores de feijão de MG, como Unaí, Paracatu e Guarda-Mor (SEAB, 2015). Os anos de 2005 e 2009 apresentaram os maiores valores de RMF referentes à $1^{a}$ safra (Figura $3 a$ ). Considerando essa safra, somente em 2005 foi notada anomalia positiva significativa da Tmín $\left(0,32{ }^{\circ} \mathrm{C}\right)$ (Tabela 4). A distribuição e intensidade da precipitação foram uniformes em ambos os anos, com algumas ocorrências de chuva acima da climatologia, principalmente na estação chuvosa de 2008-2009, apresentando poucos dias sem chuva e taxas máximas de precipitação não ultrapassando $20 \mathrm{~mm} \cdot \mathrm{dia}^{-1}$ (Figura 4a). As chuvas bem distribuídas desde a DMS até a colheita, em 2005 e 2009, contribuíram para os altos valores de RMF nesses anos. Além disso, a diminuição da amplitude térmica devido à anomalia positiva de Tmín em 2005 favoreceu ainda mais o RMF desse ano, uma vez que não ocorreram condições climáticas extremas, permitindo assim o pleno desenvolvimento do feijão e o máximo RMF (EVANGELISTA et al., 2015).

$\mathrm{Na} 2^{a}$ safra, o maior RMF foi observado em 2015 (Figura 3a), o qual apresentou anomalia positiva da Tmáx $\left(0,63^{\circ} \mathrm{C}\right)$ durante o ciclo total do feijão (Tabela 3). Apesar de apresentar chuvas abaixo da média durante os estágios iniciais do feijão - V1 à V3 - (meados de janeiro a início de fevereiro), posteriormente houve um pico de $20 \mathrm{~mm}$.dia ${ }^{-1}$ e se reestabeleceu em meados de fevereiro, apresentando pouca oscilação em sua distribuição e intensidade a partir deste mês (Figura 4a). Esse pico de $20 \mathrm{~mm} \mathrm{dia}^{-1}$ pode ter abastecido o conteúdo de água no solo e provavelmente, não prejudicou a emissão dos primórdios foliares (V1) e do aparecimento da primeira folha trifoliolada (V3), tanto em semeaduras precoces (decêndio 01: 01/01) quanto tardios (decêndio 04: 09/02). Além disso, o feijão cultivado na $2^{a}$ época (safra da seca) é mais resistente à condição de precipitação reduzida e, segundo Balardin et al. (2000) e Silva et al. (2011), a exigência hídrica do feijão é máxima durante o 
florescimento (anterior a maturação fisiológica), que neste caso vai desde o início de março a abril, quando as chuvas foram próximas a média climatológica.

Ainda na MMG-1, na $3^{a}$ safra, o maior RMF ocorreu em 2013, em que foi notado anomalia positiva significativa de Tmáx (Tmín) de $0,53{ }^{\circ} \mathrm{C}\left(0,9{ }^{\circ} \mathrm{C}\right)$ (Tabela 3 e 4, respectivamente). A precipitação durante essa safra foi semelhante à climatologia, com pouca ou nenhuma taxa pluviométrica (Figura 4a). Durante essa safra foram notadas as menores Tmín (15 ${ }^{\circ} \mathrm{C}$ ) e Tmáx (22 ${ }^{\circ} \mathrm{C}$ ) médias nesta macrorregião (não mostrados). Logo, as anomalias positivas em ambas as temperaturas fizeram com que a região apresentasse

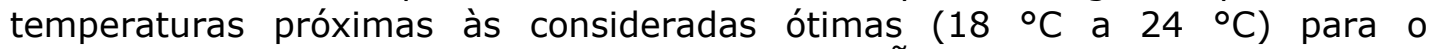
desenvolvimento do feijão (VIEIRA, 1967; FERRÃO et al., 2006) contribuindo para o maior rendimento.

Em contrapartida, os anos que apresentaram maior queda no rendimento na MMG-1 para a $1^{a}$ safra foram 2006 e 2013, com destaque para 2006; na $2^{a}$ safra foi 2013 e $3^{a}$ safra, 2015. Na $1^{a}$ safra, em 2006 ocorreu anomalias negativas significativas de Tmáx $\left(-0,93^{\circ} \mathrm{C}\right)$ e Tmín $\left(-0,5^{\circ} \mathrm{C}\right)$. Além disso, houve perfis heterogêneos de precipitação, com chuva acima da média entre novembro e dezembro de 2005, e abaixo da média do final de dezembro de 2005 ao início de março de 2006, assim como do início de dezembro de 2012 a janeiro de 2013 (Figura 5a). Essas datas coincidem com o período reprodutivo do feijão, os quais são sensíveis à deficiência hídrica (SILVA et al., 2011). A combinação das anomalias negativas de temperatura (Tmáx e Tmín) com as variações no perfil de precipitação influenciaram o baixo RMF nesses anos tanto para semeaduras antecipadas (decêndio 29: 08/10) quanto para semeaduras tardias (decêndio 33: 26/11). Essa associação pode alongar a duração do ciclo do feijão, expondoo às condições adversas e à ocorrência de patógenos como a ferrugem e a mancha-angular (VIEIRA et al., 1991), assim como afetar o enchimento de grãos devido à deficiência hídrica do período.

Já na $2^{a}$ safra, em 2013 o menor RMF deve ter ocorrido em função da associação da anomalia positiva da Tmín $\left(0,45^{\circ} \mathrm{C}\right.$ ) (Tabela 4), precipitação acima da média nos primeiros estágios do feijão (V1 a V3) (meados de janeiro a início de fevereiro) e posteriormente abaixo da média até meados de março e seu restabelecimento em abril (Figura $5 a$ ). Como o feijão é sensível ao déficit hídrico por possuir sistema radicular pouco desenvolvido, a redução da absorção de água do solo interfere na disponibilidade de água às plantas (SILVA et al., 2011), mesmo que em curtos períodos e no estágio inicial. Logo, tal situação prejudica diretamente o RMF. 
Tabela 3 - Anomalias significativas $(p<0,05)$ de temperatura máxima do ar considerando o ciclo total do feijão comum nas quatro macrorregiões de MG (MMG-1, MMG-2, MMG-3 e MMG-4) e safras (S-1, S-2 e S-3) no período de 2003 a 2015.

\begin{tabular}{|c|c|c|c|c|c|c|c|c|c|c|c|c|}
\hline \multirow{2}{*}{ ANO } & \multicolumn{3}{|c|}{ MMG-1 } & \multicolumn{3}{|c|}{ MMG-2 } & \multicolumn{3}{|c|}{ MMG-3 } & \multicolumn{3}{|c|}{ MMG-4 } \\
\hline & S-1 & S-2 & $S-3$ & S-1 & S-2 & S-3 & S-1 & S-2 & S-3 & S-1 & S-2 & S-3 \\
\hline 2003 & -- & -- & -- & -- & 0,62 & -- & -- & -- & -- & -- & -- & -- \\
\hline 2004 & -- & $-1,93$ & $-1,10$ & -- & $-1,44$ & -- & -- & $-0,90$ & -- & -- & $-0,87$ & -- \\
\hline 2005 & -- & -- & -- & -- & -- & -- & -- & -- & -- & -- & 0,56 & -- \\
\hline 2006 & $-0,93$ & -- & $-1,05$ & $-0,99$ & -- & $-1,06$ & $-0,75$ & -- & -- & $-0,83$ & -- & $-1,08$ \\
\hline 2007 & -- & -- & 0,49 & $-1,00$ & -- & -- & $-0,78$ & 0,84 & 0,66 & $-0,62$ & 0,85 & 0,95 \\
\hline 2008 & 0,92 & $-0,63$ & -- & -- & -- & -- & -- & $-0,76$ & -- & -- & -- & -- \\
\hline 2009 & -- & -- & -- & $-0,76$ & -- & -- & -- & -- & -- & -- & -- & $-0,76$ \\
\hline 2010 & 0,73 & 0,61 & -- & 1,30 & 0,74 & -- & 0,72 & -- & -- & 0,54 & 0,77 & -- \\
\hline 2011 & -- & -- & -- & -- & -- & -- & -- & -- & 0,90 & -- & -- & -- \\
\hline 2012 & $-1,52$ & -- & 0,55 & $-1,50$ & -- & -- & $-1,31$ & -- & -- & $-1,02$ & 0,57 & -- \\
\hline 2013 & -- & -- & 0,53 & -- & -- & -- & 0,63 & $-0,85$ & $-1,05$ & 0,67 & $-0,72$ & $-1,38$ \\
\hline 2014 & -- & -- & -- & 0,75 & 0,58 & -- & -- & 1,02 & -- & -- & -- & -- \\
\hline 2015 & 1,01 & 0,63 & -- & 0,94 & $-0,57$ & 1,21 & 1,03 & -- & 1,18 & 0,64 & $-0,86$ & 1,03 \\
\hline
\end{tabular}

Já a 3a safra em 2015, apesar da precipitação ser próxima da climatologia do período, a magnitude da anomalia positiva de Tmín foi elevada $\left(1,29{ }^{\circ} \mathrm{C}\right)$, impactando no menor RMF. Temperaturas elevadas causam abortamento floral, redução do número de grãos por vagem, grãos reduzidos, e vagens defeituosas, os quais afetam diretamente o rendimento (DIDONET; SILVA, 2004; SILVA et al., 2007; BARBOSA; GONZAGA, 2012).

Considerando a MMG-2, os maiores RMF na $1^{\text {a }}$ safra foram identificados em 2003 e 2014, na 2a safra em 2004 e 2012 e na 3a safra em 2010 (Figura 3b). Na $1^{\text {a }}$ safra, em 2003 (2014), ocorreu anomalia positiva significativa da Tmín (Tmáx) de $0,57{ }^{\circ} \mathrm{C}\left(0,75^{\circ} \mathrm{C}\right)$, como pode ser vista na Tabela 4 (3). A precipitação foi uniforme (poucas oscilações), com valores máximos de até 40 mm.dia-1 em 2003. Já a estação chuvosa de 2013-2014 apresentou valores elevados de precipitação (aproximadamente $50 \mathrm{~mm}$.dia-1 ${ }^{-1}$ ), porém com ausência e pouca chuva no final da safra (janeiro e fevereiro de 2014), o que é desejável (Figura 4b). Nota-se que, de modo geral, a MMG-2 apresenta taxa de precipitação acima das demais MMG, sendo mais propícia ao cultivo do feijão. Além disso, a pouca ou ausência de precipitação no final da safra, principalmente em 2014, pode ter contribuído para melhor colheita e aproveitamento dos grãos (DIDONET; SILVA, 2004; HEINEMANN et al., 2009).

Na $2^{a}$ safra, a associação de anomalias negativas de Tmáx e Tmín $(-1,44$ e $-0,51{ }^{\circ} \mathrm{C}$, respectivamente) com o perfil uniforme de precipitação ( $\leq 30$ mm.dia-1 de fevereiro a maio de 2004) (Figura 4b) contribuíram para o maior RMF em 2004, tanto em semeaduras precoces (decêndio 02: 20/01) quanto em tardias (decêndio 05: 19/02). Considerando a $3^{a}$ safra, a anomalia negativa significativa na Tmín $\left(-0,7^{\circ} \mathrm{C}\right)$ associada ao padrão climatológico da distribuição e intensidade da precipitação, exceto para outubro (precipitação de até $15 \mathrm{~mm}^{-}$ ${ }^{1}$ ) (Figura 4b) favoreceram para o maior RMF em 2010. 
Tabela 4 - Anomalias significativas $(p<0,05)$ de temperatura mínima do ar considerando o ciclo total do feijão comum nas quatro macrorregiões de MG (MMG-1, MMG-2, MMG-3 e MMG-4) e safras (S-1, S-2 e S-3) no período de 2003 a 2015.

\begin{tabular}{|c|c|c|c|c|c|c|c|c|c|c|c|c|}
\hline \multirow{2}{*}{ ANO } & \multicolumn{3}{|c|}{ MMG-1 } & \multicolumn{3}{|c|}{ MMG-2 } & \multicolumn{3}{|c|}{ MMG-3 } & \multicolumn{3}{|c|}{ MMG-4 } \\
\hline & S-1 & S-2 & S-3 & S-1 & S-2 & S-3 & S-1 & S-2 & S-3 & S-1 & S-2 & S-3 \\
\hline 2003 & 0,38 & -- & -- & 0,57 & -- & -- & 0,69 & -- & -- & 0,50 & -- & -- \\
\hline 2004 & 0,46 & -- & -- & -- & $-0,51$ & $-0,61$ & -- & -- & $-0,79$ & -- & -- & -- \\
\hline 2005 & 0,32 & 0,34 & -- & -- & -- & 0,80 & -- & -- & -- & -- & 0,32 & 0,86 \\
\hline 2006 & $-0,50$ & 0,26 & $-1,13$ & $-0,61$ & 0,39 & -- & $-0,56$ & -- & -- & -- & 0,55 & -- \\
\hline 2007 & -- & $-0,28$ & -- & -- & -- & -- & -- & 0,25 & -- & -- & -- & -- \\
\hline 2008 & -- & -- & $-1,35$ & -- & 0,27 & -- & -- & -- & -- & -- & -- & -- \\
\hline 2009 & -- & -- & -- & -- & 0,30 & 1,54 & -- & 0,56 & 1,58 & -- & -- & 0,97 \\
\hline 2010 & -- & -- & -- & 0,48 & -- & $-0,70$ & 0,78 & -- & -- & 0,38 & -- & -- \\
\hline 2011 & -- & $-0,25$ & $-0,85$ & -- & -- & -- & -- & 0,26 & -- & -- & -- & -- \\
\hline 2012 & $-0,72$ & $-0,46$ & 0,83 & $-1,01$ & -- & -- & $-0,88$ & $-0,43$ & $-0,84$ & $-0,88$ & -- & -- \\
\hline 2013 & -- & 0,45 & 0,90 & -- & -- & -- & -- & -- & -- & -- & $-0,54$ & $-0,85$ \\
\hline 2014 & -- & -- & -- & -- & -- & $-0,69$ & -- & -- & -- & $-0,40$ & $-0,62$ & -- \\
\hline 2015 & -- & -- & 1,29 & $-0,46$ & -- & 0,73 & -- & -- & 1,47 & -- & -- & 0,69 \\
\hline
\end{tabular}

Por outro lado, 2006 foi marcado pelo menor RMF para a $1^{\text {a }}$ safra na MMG-2 (Figura 3b). Nesse ano foram registradas anomalias negativas significativas de Tmáx $\left(-0,99^{\circ} \mathrm{C}\right)$ e Tmín $\left(-0,61^{\circ} \mathrm{C}\right)$. A precipitação foi uniforme e acima da média de novembro a final de dezembro de 2005, porém, após esse período houve uma diminuição nessa variável, assim como pode-se notar dias sem chuva até o final da safra (final de janeiro e início de fevereiro de 2006) (Figura 5b). Semelhante à $1^{a}$ safra da MMG-1, anomalias negativas foram registradas em ambas as temperaturas e padrão de chuva com mesmo perfil, o que ocasionou, também, um dos menores RMF dessa safra em ambas as MMG.

Considerando a 2a safra, em 2003 e 2010 observou-se os menores valores de RMF (Figura $3 \mathrm{~b}$ ). Nesses anos foram registradas anomalias positivas da Tmáx $\left(0,62\right.$ e $0,74{ }^{\circ} \mathrm{C}$, respectivamente), chuvas abaixo da média no início da safra (fevereiro). Além disso, a precipitação teve maior oscilação, ou seja, maiores períodos com pouca ou nenhuma chuva, e de menor intensidade em 2003 do que em 2010 (Figura 5b). O aumento da amplitude térmica devido às anomalias positivas da Tmáx combinadas com a oscilação das chuvas, além de pouca precipitação nos primeiros subperíodos do feijão (V0 a V3), podem ter desfavorecido o RMF na safra desses anos (EVANGELISTA et al., 2015).

Já o menor RMF identificado na $3^{a}$ safra ocorreu em 2011, ano em que não foram observadas anomalias significativas de temperatura do ar, porém a precipitação foi abaixo dos valores climatológicos do período até meados de outubro, com o aumento considerável na taxa de precipitação (até $25 \mathrm{~mm} \cdot \mathrm{dia}^{-1}$ ) próximo à época de colheita da $3^{a}$ safra (final de outubro), o que influenciou no baixo valor de RMF neste ano, como verificado por Heinemann et al. (2009).

De modo geral, apesar da presença de anomalias positiva ou negativa, tanto na Tmáx como na Tmín na MMG-2, nota-se uma possível predominância da precipitação no comportamento do RMF, já que em anos onde o RMF foi alto ocorreram chuvas uniformes e próximas a climatologia durante todo o ciclo total do feijão, enquanto que nos anos com menores RMF as chuvas apresentaram grandes oscilações ou permaneceram abaixo da média do período. Segundo Ano 14 - Edição Especial Dossiê Climatologia de Minas Gerais - NOV 2018 
Heinemann et al. (2009), o consumo médio diário de água pelo feijoeiro varia de acordo com o local, estágio de desenvolvimento e época de semeadura, sendo que em MG esse valor médio deve estar entre 3 a $5 \mathrm{~mm}$.dia ${ }^{-1}$. Em casos de déficit hídrico, a redução da área foliar e o fechamento estomático são as principais estratégias de defesa da planta (TAIZ; ZEIGER, 2013) e como consequência, há redução das trocas gasosas (transpiração e assimilação de CO2 para a realização da fotossíntese). Esses fatores aliados são os responsáveis pela redução da produtividade e da qualidade da produção do feijão (SILVA et al., 2011; HEINEMANN et al., 2017). Por outro lado, o excesso de chuvas pode ser prejudicial à qualidade dos grãos após a maturação fisiológica (VIEIRA, 1978; SILVA, 2005) e favorecer a proliferação de certos patógenos (VIEIRA, 2004) em todos os estágios de desenvolvimento do feijão.

Com relação a MMG-3, 2005 destacou-se por apresentar o maior RMF da $1^{\text {a }}$ safra (Figura 3c), no qual não foram notadas anomalias significativas de temperatura do ar (Tabelas 3 e 4). A precipitação apresentou variações na

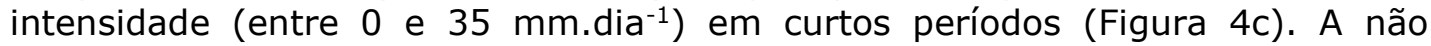
ocorrência de anomalias significativas de Tmáx e Tmín, além de poucos e curtos períodos de precipitação abaixo da média, contribuíram para o alto RMF.

Diferente da $1^{a}$ safra, o maior RMF na $2^{a}$ safra foi identificado em 2012, o qual apresentou anomalia negativa significativa de Tmín $\left(-0,43^{\circ} \mathrm{C}\right)$ (Tabela 4 ) e oscilação na precipitação durante o ciclo total do feijão (Figura 4c). Em meados de fevereiro a março de 2012 as chuvas foram menos intensas que a climatologia retornando a valores próximos e acima da média climatológica do período em meados de março até a colheita (maio de 2012). Apesar da anomalia da Tmín, a Tmín média $\left(16,7^{\circ} \mathrm{C}\right)$ foi superior à temperatura base $\left(\sim 10^{\circ} \mathrm{C}\right)$ e a Tmáx média $\left(28,5^{\circ} \mathrm{C}\right)$ foi inferior à Tmáx limite requerida pelo feijão $\left(30^{\circ} \mathrm{C}\right.$ ) (MALUF et al., 2001; SILVA et al., 2007, MIRANDA; JÚNIOR, 2010), fatores que favoreceram o pleno desenvolvimento do feijão. Além disso, a precipitação diária foi abaixo da média somente durante o período de crescimento vegetativo do feijão (0-40 DAS), com chuvas acima da média após esse período, o que restabeleceu o conteúdo de água no solo na fase reprodutiva, não prejudicando o RMF (SILVA, 2005; HEINEMANN et al., 2009). Portanto, a anomalia negativa da Tmín durante a $2^{a}$ safra reduziu as perdas de água para a atmosfera, minimizando a necessidade hídrica do feijão. 


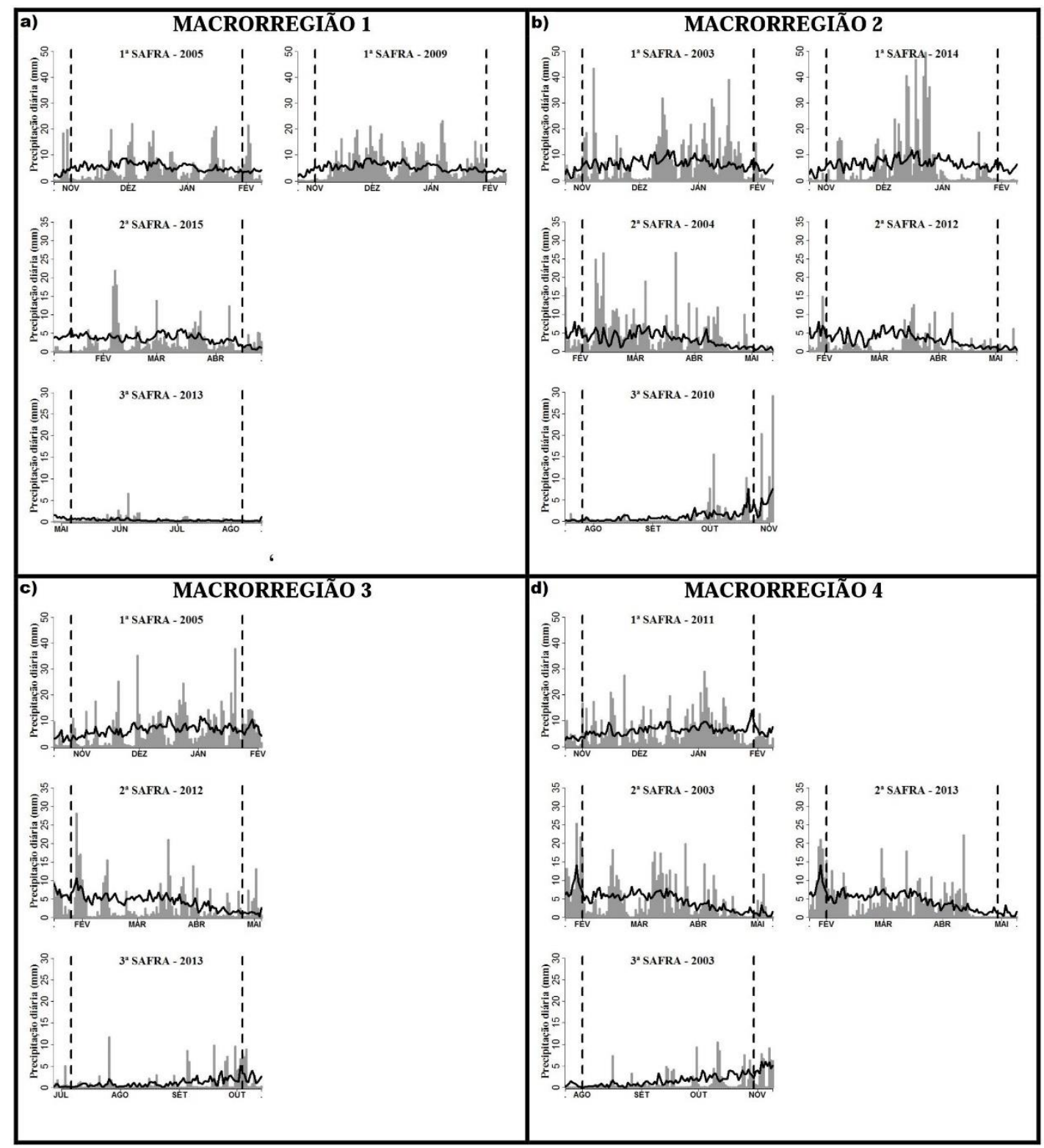

Figura 4 - Precipitação diária (mm.dia-1, barras em cinza) nas quatro macrorregiões: MMG-1(a), MMG-2 (b), MMG-3 (c) e MMG-4 (d), referentes às safras que apresentaram os maiores RMF (2003-2015). A linha preta representa a média da precipitação diária (1998-2015) e as linhas verticais tracejadas, a data média de semeadura (esquerda) e média de colheita (direita) do feijão.

O maior RMF da $3^{a}$ safra ocorreu em 2013, no qual foi observada anomalia negativa da Tmáx $\left(-1,05^{\circ} \mathrm{C}\right)$ e precipitação próxima da climatologia do

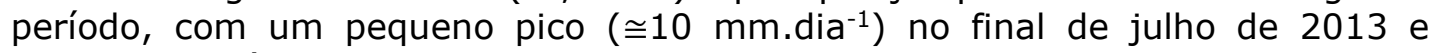
chuvas esporádicas de baixa intensidade a partir de setembro (Figura 4c), sendo ideal ao cultivo do feijão. A anomalia negativa da Tmáx representou uma temperatura máxima média de $26,1^{\circ} \mathrm{C}$, não extrapolando $30^{\circ} \mathrm{C}$, o qual é 
considerado o limite para o pleno desenvolvimento do feijão (MALUF et al., 2001, SILVA et al., 2007).

Os anos de menor RMF na MMG-3 foram variáveis entre as safras, similar ao observado nas MMG-1 e 2. Considerando a $1^{\text {a }}$ safra, 2007 apresentou anomalia negativa significativa da Tmáx $\left(-0,78{ }^{\circ} \mathrm{C}\right)$, o que seria desejável ao feijão, principalmente nas semeaduras precoces (decêndio 25: 29/08). No entanto, houve predomínio de chuvas acima da média climatológica, principalmente no final da safra (Figura $5 \mathrm{c}$ ), o que pode ter prejudicado a colheita e a qualidade dos grãos (VIEIRA et al., 1991; ÁVILA et al., 2010; MONTEIRO et al., 2010; POSSE et al., 2010). As chuvas acima da média estão relacionadas diretamente com a cobertura de nuvem, a qual contribui para a pouca elevação da Tmáx, uma vez que a refletividade das nuvens impede que a radiação de onda curta aqueça a superfície, causando anomalia de temperatura.

Já na $2^{a}$ safra, 2007 e 2014 foram os anos com menor RMF, sendo registradas anomalias positivas da Tmáx $\left(0,84\right.$ e $1,02{ }^{\circ} \mathrm{C}$, respectivamente) e somente em 2007, anomalia positiva da Tmín $\left(0,25^{\circ} \mathrm{C}\right)$. A precipitação na estação chuvosa de 2006-2007 foi acima da média até meados de fevereiro de 2007, revertendo para abaixo da média climatológica até a ausência de chuva em meados de março, com alguns picos até o final da safra (final de abril). Em 2014 houve chuva abaixo da média e ausência durante grande parte do ciclo do feijão (Figura 5c). Pode-se notar que o perfil apresentado em ambos os anos foi o oposto daquele visto na $1^{\text {a }}$ safra de 2007 nessa mesma região. O aumento de temperatura tende a elevar a evapotranspiração, fazendo com que as plantas percam água para a atmosfera em taxas elevadas. No entanto, com a redução da precipitação, a oferta de água é inferior à taxa evaporativa, resultando em situação de déficit hídrico. Nesses caso, as principais estratégias de defesa do feijão é a redução da área foliar e fechamento estomático (DIDONET; SILVA, 2004; PIMENTEL et al., 2013; DARKWA et al., 2016) e como consequência, há redução das trocas gasosas, o que resulta na redução da estatura, tamanho e número de vagens, prejudicando o RMF e a qualidade da produção (DIDONET; SILVA, 2004; SILVA et al., 2011).

Na $3^{a}$ safra o menor RMF foi em 2014 (Figura 3c). No entanto, não foram identificadas anomalias significativas de temperatura, porém a precipitação apresentou oscilações com picos acima da média somente em julho, que representa os estágios V0 a V3 (Figura 2) nas semeaduras precoces (decêndio 10: 10/07), próximo ao valor médio entre agosto e setembro e, posteriormente, abaixo da média (Figura $5 \mathrm{c}$ ). As chuvas abaixo da média em setembro podem ter levado a situação de deficiência hídrica na fase de aparecimento dos botões florais (R5) nas semeaduras tardias (decêndio 21: 29/07) e início da formação e enchimento da vagem ( $R 7$ e R8) nas semeaduras precoces (decêndio 10: 10/07), prejudicando o RMF na $3^{a}$ safra da MMG-3.

Assim como nas demais MMG, a MMG-4 também apresentou diferença do RMF entre os anos e safras. Considerando a $1^{\text {a }}$ safra, o seu maior RMF ocorreu em 2011, enquanto o menor em 2013 (Figura 3d). Em 2011 não ocorreu anomalias significativas de temperatura e a precipitação foi uniformemente distribuída durante toda a safra, não ultrapassando $25 \mathrm{~mm}$.dia-1 e períodos curtos abaixo da média climatológica (Figura 4d), padrão semelhante ao observado para a mesma safra na MMG-3, corroborando com a afirmativa que o feijão é sensível às variações de temperatura e precipitação, a qual influencia 
seu rendimento (EVANGELISTA et al., 2015; HEINEMANN et al., 2017). Por outro lado, 2013 teve o menor RMF, ano no qual foi observada anomalia positiva da Tmáx $\left(0,67^{\circ} \mathrm{C}\right)$, assim como oscilação no perfil da precipitação, com valores

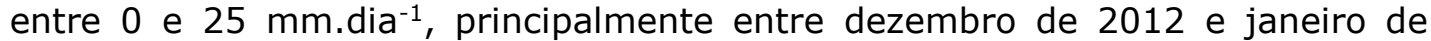
2013, coincidindo com os estágios reprodutivos (R6-R8) (Figura 5d). Além disso, as chuvas foram constantes durante a colheita. Tais fatores combinados (Tmáx elevada, oscilação da precipitação com pouca chuva durante o estágio reprodutivo e chuvas durante a colheita) reduziram o RMF da $1^{\text {a }}$ safra na MMG4. A temperaturas máximas elevadas ( $\geq 30^{\circ} \mathrm{C}$ ) causam abortamento floral, diminuição do número de grão/vagem, menor peso de grãos (EMBRAPA, 2003; DIDONET; SILVA, 2004; SILVA et al., 2007), o que reduz o RMF.

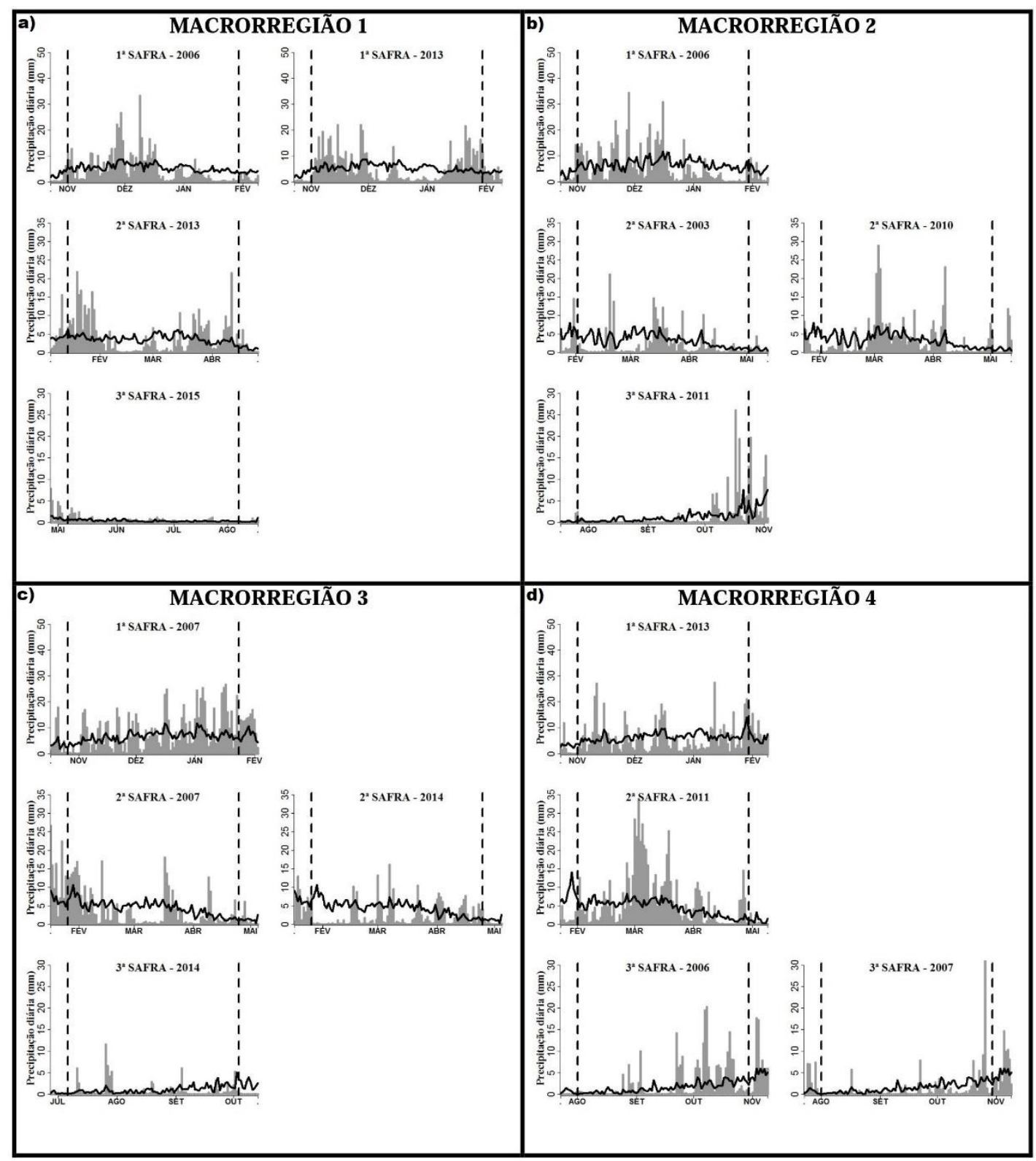

Ano 14 - Edição Especial Dossiê Climatologia de Minas Gerais - NOV 2018 
Figura 5 - Precipitação diária ( $m m \cdot d_{i a}^{-1}$, barras em cinza) nas quatro macrorregiões: MMG $^{-1}(a)$, MMG-2 (b), MMG-3 (c) e MMG-4 (d), referentes às safras que apresentaram os menores RMF (2003-2015). A linha preta representa a média da precipitação diária (1998-2015) e as linhas verticais tracejadas, a data média de semeadura (esquerda) e média de colheita (direita) do feijão.

Com relação à 2a safra em 2003 e 2013, a precipitação foi uniforme principalmente durante a fase reprodutiva do feijão (a partir de março), com valores $\leq 20 \mathrm{~mm}$. dia-1, com curtos períodos de valores abaixo da média. Além disso, em 2003 não foram observadas anomalias significativas de Tmáx e Tmín, enquanto em 2013 teve anomalias negativas da Tmáx $\left(-0,72{ }^{\circ} \mathrm{C}\right)$ e Tmín $(-0,54$ $\left.{ }^{\circ} \mathrm{C}\right)$. Vale enfatizar que, além desses fatores considerados próximos das condições ótimas para o máximo rendimento do feijão, não se observou precipitação durante a colheita, favorecendo o RMF (HEINEMANN et al., 2009; BOTELHO et al., 2010; BARBOSA; GONZAGA, 2012). Já na $3^{a}$ safra, o maior RMF observado em 2003, ocorreu em função da não ocorrência de anomalias significativas de Tmáx e Tmín, assim como a precipitação pouco abaixo da média do período e esporádicos picos de próximos de $10 \mathrm{~mm}$.dia-1 (Figura 4d).

Os menores RMF ocorreram em 2011 ( $2^{a}$ safra) e em 2006 e 2007 ( $3^{a}$ safra) (Figura 3d). No caso da $2^{a}$ safra, apesar da não ocorrência de anomalias significativas da temperatura do ar, a precipitação foi predominantemente acima da média, com valores de até $30 \mathrm{~mm}$ dia $^{-1}$ (Figura $5 \mathrm{~d}$ ). Isso ressalta a sensibilidade do feijoeiro no que diz respeito ao excesso de água, que foi notado nos estágios V3 a R3, o que prejudicou o desenvolvimento vegetativo e reprodutivo do feijão (SILVEIRA; STONE, 2004; SILVA, 2005; HEINEMANN et al., 2009; ÁVILA et al., 2010). No caso da $3^{3}$ safra ocorreram anomalias negativa da Tmáx em $2006\left(-1,08{ }^{\circ} \mathrm{C}\right)$ e positiva em 2007 (0,95 $\left.{ }^{\circ} \mathrm{C}\right)$. Além disso, em ambos os anos houve precipitação acima da média (Figura $5 \mathrm{~d}$ ), principalmente na safra de 2006 , sendo que os maiores valores de precipitação foram notados no final de outubro e início de novembro, período que coincide com a colheita, tanto em semeaduras precoces (decêndio $21: 20 / 07$ ) quanto em semeaduras tardias (decêndio 23: 18/08). Como as cultivares de feijão cultivadas nessa safra estão adaptados a pouca chuva, o excesso ocorrido nesses anos aliado às anomalias de Tmáx podem ter intensificado a queda do RMF e a qualidade dos respectivos grãos.

Com base nessas informações nota-se que o RMF em MG apresenta variações entre as safras e MMG durante o período estudado. Dentre os menores (maiores) valores de RMF foi possível notar frequentes oscilações na distribuição/intensidade das chuvas e excesso, principalmente, na época da colheita (chuvas bem distribuídas e pouca/ausência de chuva na colheita). 0 perfil das anomalias de Tmáx e Tmín mostrou oposto entre a $1^{a}$ e $2^{a}$ safra, independente da MMG, e não foi notado um padrão predominante destas anomalias na $3^{a}$ safra.

\section{CONCLUSÃO}

Houve variações nas associações entre o RMF e as anomalias de Tmáx e Tmín juntamente com a distribuição da precipitação entre as três safras e as MMG. De maneira geral, o RMF mostrou grande sensibilidade aos padrões de precipitação. Além disso, as principais características notadas foram: 
1.Nos anos com maiores RMF, a $1^{a}\left(2^{a}\right)$ safra apresenta predomínio de anomalias positivas (negativas) de Tmáx e/ou Tmín, independente da MMG;

2.Independentemente da safra e da MMG, nos anos que ocorreram maiores RMF não foram observadas grandes variações de precipitação, sendo uniforme durante todo o ciclo;

3. Nos anos com menores RMF, a $1^{a}\left(2^{a}\right)$ safra apresenta predomínio de anomalias negativas (positivas) de Tmáx e/ou Tmín, independente da MMG;

4.Nos anos com menores RMF, há grande variabilidade na intensidade e distribuição da precipitação, ou esta encontra-se acima da média climatológica, principalmente na época da colheita.

\section{AGRADECIMENTOS}

À Fundação de Amparo à Pesquisa do Estado de Minas Gerais (FAPEMIG) pelo aporte financeiro e concessão de bolsa; ao Instituto Nacional de Meteorologia (INMET) e ao Centro de Previsão de Tempo e Estudos Climáticos do Instituto Nacional de Pesquisas Espaciais (CPTEC/INPE) pela disponibilização dos dados de temperatura do ar e precipitação, respectivamente.

\section{REFERÊNCIAS BIBLIOGRÁFICAS}

ASSUNÇÃO, P. E. V.; WANDER, A. E. Competitividade do sistema agroindustrial do feijão-comum no Estado de Goiás. Scientia Plena, v. 10, n. 7, p. 1-12, 2014.

ÁVILA, M. R.; BARIZÃO, D. A. O.; GOMES, E. P.; FEDRI, G.; ALBRECHT, L. P. Cultivo do feijoeiro no outono/inverno associado à aplicação de bioestimulante $\mathrm{e}$ adubo foliar na presença e ausência de irrigação. Scientia Agrária, Curitiba, v. 11, n. 3, p. 221-230, 2010.

ÁVILA, L. F.; MELLO, C. R.; YANAGI, S. N. M.; NETO, O. B. S. Tendências de temperaturas mínimas e máximas do ar no Estado de Minas Gerais. Pesquisa Agropecuária Brasileira, v. 49, n. 4, p. 247-256, 2014.

BARBOSA, F. R.; GONZAGA, A. C. O. Informações técnicas para o cultivo do feijoeiro-comum na Região Central-Brasileira: 2012- 2014. Santo Antônio de Goiás: Embrapa Arroz e Feijão. 247 p, 2012. Disponível em: <http://www.cnpaf.embrapa.br/transferencia/informacoestecnicas/publicaco esonline/seriedocumentos_272.pdf>. Acesso em: 06 abr de 2017.

BALARDIN, R. S.; COSTA, E. C. C.; RIBEIRO, N. D.; DUTRA, L. M. C.; COSTA, I. F. D. Feijão, recomendações técnicas para cultivo no Rio Grande do Sul. 2000. Santa Maria, Comissão Estadual de Pesquisa do Feijão-CEPEF, 2000.

BOTELHO, F. J. E.; GUimARÃES, R. M.; OLIVEIRA, J. A.; EVANGELISTA, J. R. E.; ELOI, T. A.; BALIZA, D. P. Desempenho fisiológico de sementes de feijão colhidas em diferentes períodos do desenvolvimento. Ciência e Agrotecnologia, v. 34, n. 4, p. 900-907, 2010.

CARAMORI, P. H.; GONÇALVES, S. L.; WREGE, M. S.; CAVIGLIONE, D. O.; FARIA, R. T.; LOLLATO, M. A.; MARIOT, E. J.; KRANZ, W. M.; PARRA, M. S.; BIANCHINI, A. Zoneamento de riscos climáticos e definição de datas de 
semeadura para o feijão no Paraná. Revista Brasileira de Agrometeorologia, Passo Fundo, v.9, n.3, (No Especial: Zoneamento Agrícola), p.477-485, 2001.

CIAT - Centro Internacional de Agricultura Tropical. Etapas de desarrollo de la planta de frijol común. Eds.: F. Fernàndez; P.Gepts; M. López. Cali, Colombia. CIAT. 1983. 26p.

DARKWA, K.; AMBACHEW, D.; MOHAMMED, H.; ASFAW, A.; BLAIR, M. W. Evaluation of common bean (Phaseolus vulgaris L.) genotypes for drought stress adaptation in Ethiopia. The crop journal, v. 4, n. 5, p. 367-376, 2016.

DIDONET, A. D.; SILVA, S. C. Elementos climáticos e produtividade do feijoeiro. Informe Agropecuário, Belo Horizonte, v.25, n.223, p.13-19, 2004.

DOURADO NETO, D.; FANCELLI, A. L. Produção de feijão. Guaíba: Agropecuária, 2000. 385 p.

EMBRAPA - Empresa Brasileira de Pesquisa Agropecuária. Feijão: o produtor pergunta, a Embrapa responde. 2a Edição. Brasília. EMBRAPA. 2014. 247p.

EVANGELISTA, M. L. A.; JÚNIOR, A. F. L.; OLIVEIRA, I. P.; BRITO, G. S.; SILVA, M. C.; COSTA, F. R. Avaliação do tempo de germinação de diferentes variedades de feijão carioca cultivada na região do Centro-Oeste do Brasil. Revista de Ciências Agrárias, v. 8, n. 5, 2015.

FAO - Organização das Nações Unidades para Agricultura e Alimentação. Perspectivas Agrícolas 2015-2024. 2015.Disponível em:< http://www.fao.org/3/a-i47610.pdf>. Acesso em 12 de abr de 2018.

FERRÃO, M. A. G.; VIEIRA, C.; CRUZ, C. D.; CARDOSO, A. A. Comportamento de cultivares de feijão e de suas gerações híbridas, no inverno. Revista Ceres, v. 53, n. 306, 2006.

GAN, M. A.; KOUSKY, V. E.; ROPELEWSKI, C. F. The South America monsoon circulation and its relationship to rainfall over west-central Brazil. Journal of climate, v. 17, n. 1, p. 47-66, 2004.

GAN, M. A.; SANTOS, L. F.; LIMA, J. R. A.; AFONSO, J. A. S.; SILVA, A. B. Monção da América do Sul. Climanálise. Edição Comemorativa de 30 anos do Climanálise. São José dos Campos, 2016.

GARCIA, S. R.; CALHEIROS, A. J. P.; KAYANO, M. T. Revised method to detect the onset and demise dates of the rainy season in the South American Monsoon areas. Theoretical and Applied Climatology, v. 126, p.481-491, 2016.

GARCIA, S. R.; KAYANO, M. T.; CALHEIROS, A. J. P.; ANDREOLI, R. V.; SOUZA, R. A. F. Moisture and heat budgets of the south American monsoon system: climatological aspects. Theoretical and Applied Climatology, v. 130, p. 233-247, 2017.

GARCIA, S. R.; SANTOS, D. F.; MARTINS, F. B.; TORRES, R. R. Aspectos climatológicos associados ao cultivo da oliveira (Olea europaea L.) em Minas Gerais. Revista Brasileira de Climatologia, v. 22, p. 188-209, 2018.

HEINEMANN, A. B.; STONE, L. F.; SILVA, S. C. Feijão. Em: MONTEIRO, J. E.. In: Agrometeorologia dos cultivos: o fator meteorológico na produção agrícola. INMET, Brasília, p. 182-201, 2009. 
HEINEMANN, A. B.; RAMIREZ-VILLEGAS, J.; SOUZA, T. L. P. O.; DIDONET, A. D.; STEFANO, J. G.; BOOTE, K. J.; JARVIS, A. Drought impact on rainfed common bean production areas in Brazil. Agricultural and forest meteorology, $\mathrm{v}$. 225, p. 57-74, 2016.

HEINEMANN, A. B.; RAMIREZ-VILLEGAS, J.; STONE, L. F.; DIDONET, A. D. Climate change determined drought stress profiles in rainfed common bean production systems in Brazil. Agricultural and Forest Meteorology, v. 246, p. 6477, 2017.

HOFFMANN JUNIOR, L.; RIBEIRO, N. D.; ROSA, S. S.; JOST, E.; POERSCH, N. L.; MEDEIROS, S. L. P. Resposta de cultivares de feijão à alta temperatura do ar no período reprodutivo. Ciência Rural. Santa Maria, v. 37, n. 6, p. 1543-1548, 2007 .

HOOGENBOOM, G. Contribution of agrometeorology to the simulation of crop production and its application. Agricultural and Forest Meteorology, 103, p. 137$157,2000$.

IBGE - Instituto Brasileiro de Geografia e Estatística. Culturas temporárias e permanentes. Prod. agric. munic., Rio de Janeiro, v. 43, p.1-62, 2016. Disponível em: https://biblioteca.ibge.gov.br/visualizacao/periodicos/66/pam_2016_v43_br.pdf >. Acesso em: 12 abr de 2018.

JONES, J. W.; ANTLE, J. M.; BASSO, B.; BOOTE, K. J; CONANT, R. T.; FOSTER, I.; GODFRAY, H. C. J.; HERRERO, M.; HOWITT, R. E.; JANSSEN, S.; KEATING, B. A.; MUNOZ-CARPENA, R.; PORTER, C. H.; ROSENZWEIG, C.; WHEELER, T. R. Brief history of agricultural systems modeling. Agricultural systems, v. 155, p. 240-254, 2017.

LONGOBARDI, A.; VILLANI, P. Trend analysis of annual and seasonal rainfall time series in the Mediterranean area. International journal of Climatology, $v$. 30 , n. 10, p. 1538-1546, 2010.

MALUF, J. R. T.; CUNHA, G. R.; MATZENAUER, R.; PASINATO, A.; PIMENTEL, M. B. M.; CAIAFFO, M. R. Zoneamento de riscos climáticos para a cultura de feijão no Rio Grande do Sul. Revista Brasileira de Agrometeorologia, Passo Fundo, v.9, n.3 (nº Especial: Zoneamento Agrícola), p.468-476, 2001.

MAPA - Ministério da Agricultura, Pecuária e Abastecimento. Postaria 209/2013. Brasília. 2013.

MAPA - Ministério da Agricultura, Pecuária e Abastecimento. Postaria 63/2014. Brasília. 2014.

MARCO, K.; DALLACORT, R.; JÚNIOR, C. A. F.; FREITAS, P. S. L.; VILLELA, T. G. Aptidão Agroclimática e Características Agronômicas do Feijão Comum Semeado na Safra das Águas em Tangará da Serra - MT. Enciclopédia Biosfera. Goiânia, v. 8, n. 15, p. 160, 2012.

MATHOBO, R.; MARAIS, D.; STEYN, J. M. The effect of drought stress on yield, leaf gaseous exchange and chlorophyll fluorescence of dry beans (Phaseolus vulgaris L.). Agricultural Water Management, v. 180, p. 118-125, 2017. 
MIRANDA, M. N.; JÚNIOR, J. H. C. Soma térmica para o subperíodo semeaduramaturação de feijão cv. Carioca em Colorado do Oeste, Rondônia. Pesquisa Agropecuária Tropical, v. 40, n. 2, P. 180-185, 2010.

MONTEIRO, P. F. C.; ANGULO FILHO, R.; MONTEIRO, R. O. C. Efeitos da irrigação e da adubação nitrogenada sobre as variáveis agronômicas da cultura do feijão. Irriga, Botucatu, v. 15, n. 4, p. 386-400, 2010.

PANOFSKY, H. A.; BRIER, G. W. Some applications of statistics to meteorology. University Park, PA: University Park, 1968. 224p.

PIMENTEL, C.; RIBEIRO, R. V.; MACHADO, E. C.; SANTOS, M. G.; OLIVEIRA, R. F. In vivo temperature limitations of photosynthesis in Phaseolus vulgaris $L$. Environmental and experimental botany, v. 91, p. 84-89, 2013.

POSSE, S. C. P.; RIVA-SOUZA, E. M.; SILVA, G. M.; FASOLO, L. M.; SILVA, M. B.; ROCHA, M. A. M. Informações técnicas para o cultivo do feijoeiro-comum na região central-brasileira: 2009-2011. Incaper,Vitória, ES, 245 p, 2010. Disponível em: <http://www.cnpaf.embrapa.br/transferencia/informacoestecnicas/19ctcbf/19ct cbf_livrocompleto.pdf>. Acesso em: 06 abr de 2017.

REBOITA, M. S.; RODRIGUES, M.; SILVA, L. F.; ALVES, M. A. Aspectos climáticos do estado de Minas Gerais. Revista Brasileira de Climatologia, v. 17, p. 206-226, 2015.

SANTOS, L. F.; GARCIA, S. R. Início e Fim da Estação Chuvosa no Estado de Minas Gerais: Comparação de Duas Metodologias Diferentes. Revista Brasileira de Meteorologia, v. 31, n. 1, p. 92-104, 2016.

SEAB - Secretaria de Estado da Agricultura e do Abastecimento.Feijão: Análise da Conjuntura Agropecuária.Conjuntura Agropecuária.Paraná, 11 p, 2015. Disponível em: <http://www.agricultura.pr.gov.br/arquivos/File/deral/Prognosticos/2016/_feija o_2015_16.pdf>. Acesso em: 19 mai 2016.

SILVA, J. C. Épocas de menor risco de estresse hídrico e térmico para o feijoeiro na região central do Rio Grande do Sul. Dissertação (Mestrado em Engenharia Agrícola) - Universidade Federal de Santa Maria, Santa Maria, 64f., 2005.

SILVA, J. C.; HELDWEIN, A. B.; MARTINS, F. B.; STRECK, N. A.; GUSE, F. I. Risco de estresse térmico para o feijoeiro em Santa Maria, RS. Ciência Rural, Santa Maria, v. 37, n. 3, p. 643-648, 2007.

SILVA, J. C.; HELDWEIN, A. B.; RADONS, S. Z.; MALDANER, I. C.; TRENTIN, G.; GRIMM, E. L. Necessidade de irrigação para o feijoeiro na região central do Rio Grande do Sul. Revista Brasileira de Engenharia Agrícola e Ambiental, v. 15, n. 10, p. 1030-1036, 2011.

SILVEIRA, P. M.; STONE, L. F. Feijão de alta produtividade: Irrigação. Informe Agropecuário. Belo Horizonte, v. 25, n. 223, p. 74-82, 2004.

TAIZ, L.; ZEIGER; E. Fisiologia Vegetal. 5. ed. Porto Alegre: ARTMED, 2013. p.954p.

VIEIRA, C. O feijoeiro-comum: cultura, doenças e melhoramento. Viçosa: UFV, 1967. 220p. 
VIEIRA, C. Cultura do feijão. Viçosa: Imprensa Universitária, 1978. 146p.

VIEIRA, C.; ARAÚJO, G. A. de A.; CHAGAS, J. M. Efeitos das datas de plantio sobre o feijão cultivado no outono-inverno. Pesquisa Agropecuária Brasileira. $\mathrm{n}$. 26, v.6, p.863-873. 1991.

VIEIRA, C. Feijão de alta produtividade: Métodos Culturais. Informe Agropecuário. Belo Horizonte, v. 25, n. 223, p. 57-59, 2004.

VIVAN, G. A.; ROBAINA, A. D.; PEITER, M.X.; PARIZI, A. R. C.; BARBOZA, F. S.; SOARES, F. C. Rendimento e rentabilidade das culturas da soja, milho e feijão cultivados sob condições de sequeiro. Semina: Ciências Agrárias, v. 36, n. 5, 2015.

WMO - World Meteorological Organization. Guide to Agricultural Meteorological Practices.2010 Edition. n. 134, 2010. Disponível em: <http://www.wmo.int/pages/prog/wcp/agm/gamp/documents/WMO_No134_en. pdf $>$. Acesso em: 30 mar 2015.

ZHOU, J.Y.; LAU, K.M. Principal modes of interannual and decadal variability of summer rainfall over South America. International Journal of Climatology, v. 21, p. 1623-1644, 2001. 